\title{
How Slang Contributes to Euphemism in Communication: A Case Study of Widal Slang Language (WSL) of Sundanese Society in Sukabumi, West Java Indonesia
}

\author{
Lusi Susilawati ${ }^{1}$, Gugun Gunardi ${ }^{2}$, Dian Indira ${ }^{3}$, Elvi Citraresmana ${ }^{4}$ \\ lusi17001@mail.unpad.ac.id ${ }^{1}$, gugun.gunardi@unpad.ac.id², dian.indira@unpad.ac.id³, \\ elvi.citraresmana@unpad.ac.id ${ }^{4}$
}

Universitas Padjadjaran, Sumedang Indonesia ${ }^{1}$ Universitas Padjadjaran, Sumedang Indonesia ${ }^{2}$, Universitas Padjadjaran, Sumedang Indonesia ${ }^{3}$, Universitas Padjadjaran, Sumedang Indonesia ${ }^{4}$

\begin{abstract}
The article discusses the phenomena of euphemistic expressions as slang language in Sukabumi West Java Indonesia. This language is called Widal Slang Language (WSL). In order to analyze the the phenomenon of slang language usage, the researchers applied Discourse Completion Task (DCT) which was deployed to 70 adolescent respondents. The results show that there were $50 \%$ of respondents used WSL in euphemism in communicating with adults to hide embarrassment, disgusting objects and activities related to them, for comfort, to show politeness, to respect others and to avoid dispute.
\end{abstract}

Keywords: Widal Slang Language, Taboo, Euphemism

\section{Introduction}

In daily life human beings always interact and communicate in their society using language. The use of language that appears in society has different language variations. Among the language variation is slang language. People use slang as a style in communication as well as to hide something from others. Slang language could be found anywhere, one of which is at the Tipar village of Sukabumi, West Java, Indonesia. Sukabumi is a city in West Java Province, Indonesia. It is divided into two Areas; kabupaten (regency) and kota (city) both of which are known as Daerah Tingkat II (second level of local government). Each of them has an administrative area called kecamatan (sub-district) which is administered by camat (sub-district head). The city of Sukabumi has seven sub-districts, namely Citamiang, Gunung Puyuh, Cikole, Cibeureum, Baros, Lembur Situ, Warudoyong dan Gunung Puyuh. There is also a village under subdistrict called kelurahan (village) which is administered by a lurah (village chief). There are 33 (thirty-three) villages in Sukabumi city. Tipar village itself is part of Citamiang sub district which is located in the centre of the city. Most of the people in Sukabumi use Sundanese language in communication.

The slang language found in Sukabumi is called Widal Slang Language, (henceforth WSL). WSL has a particular formula, it is the change of some consonants and vowels such as the word "bumi" (house) has a consonant change into "huyi" ("b" becomes "h" and "m" becomes " $y$ "), or the word "ai" has a vowel change into "nyanyi" ("a" becomes "nya" and "i" becomes "i"). The WSL is not entirely used in conversation, it is just used in the form of code-mixing though historically it was used by a member of the Tipar community in the colonial era as a code to conceal information from colonial authorities [1]. Nowadays, WSL has become a phenomenon that Sundanese society in Sukabumi, especially those who are familiar with WSL use the slang language as an alternative in uttering taboo. Therefore the researchers were interested in analyzing the phenomenon to identify the contribution of WSL to euphemism. 


\section{Literature review}

Some researchers have conducted studies on slang language. Kulkarni and Wang [2] have analyzed the slang word formation in English. They proposed three types of word formation in English Slang; blend, clipping, and reduplicative. Amir and Azisah [3] examined the slang language in student daily conversation. The study showed that the male and female students used different slang language. Meanwhile Wu, Morstatter, and Liu [4] focused on the construction of a sentiment dictionary of slang words called "SlangSD" which has a function to identify subjective expression in short and informal text.

This study investigates the slang language usage as a euphemism used by adolescents when they are communicating with adults to avoid taboo. Slang is an informal languange used in a certain community [5] while taboo is the avoided language related to obscenities, profanities, swearing and cursing [6] which is available in one culture but might not be necessarily considered as taboo in another culture [7]. Once the Sundanese society in Sukabumi use Sundanese language in their conversation (in an informal situation), some of them will use WSL as euphemism because it is more socially acceptable to listen to especially for WSL users. What is meant by euphemism is a way to replace the inoffensive or vague words or phrase [8]. Thus euphemism is an alternative utterance to avoid or to mitigate taboo. The word nyikuy, instead of nginum (drinking), will be used to hide something shameful because in the society having drunk is forbidden in their religion (Muslim). Such phenomenon is very interesting to analyze, therefore the researchers aimed at deeply analyzing the extent of WSL contribution to euphemism as an attempt to raise and maintain Sundanese culture in this era. To analyze the phenomenon, the researchers applied Warren's method about euphemism, namely 1) formal innovation; word-formation device, phonemic modification, loan words, and 2) semantic innovation; particularization, implication, metaphors, metonym, reversals, understatement and overstatement [9].

\section{Methodology}

The study applied a qualitative method, a study focusing on social world of which the data are taken from real people and real place [10]. In analysing WSL contribution to euphemism and use a discourse completion test (DCT) in collecting data; a questionnaire given to the participant with a certain prompt [11]. The questionnaire was distributed 70 respondents in 7 sub-districts. The DCT includes 28 questions (with several situations), three multiple choices, and one free answer. The multiple choices are divided into two. The choices of A and B are taboo answers and the choice of C is WSL. The free answer (choice $\mathrm{D}$ ) is provided to let the respondent write down the words when they do not agree with the other answer (choices A, B, and C). The following is the example of DCT question;

"You're standing on a roadside and accidentally saw a child who was defecating in his pants. Next to you, there is a teenager who is also paying attention to the child. Then you have a small talk

Young boy : Euleuh eta meuni hawatos kitu nya bu (How pity that child is)

You

A. Enya, tempo cadukna meunika kamana-mana

Yes, see the caduk (a harsh word for faeces) is messy

B. Muhun Néng, taina meunika kamana-mana

That's right Néng, the tai (faeces) is anywhere.

C. Muhun néng, karunya teuing wanyina meunika kamana-mana.

You are right Néng, the wanyi (WSL) is anywhere.

D. 


\section{Result and discussion}

To identify the WSL usage for euphemism, the researchers applied eleven kinds of taboo, namely, bodies and effluvia (BE), organs and their effluvia as well as their acts $(\mathrm{OE})$, sexual organs and their activities (SO), diseases and death (DD), naming and viewing person $(\mathrm{NV})$, swearing $(\mathrm{S})$, privacy $(\mathrm{P})$, underwear(U), food and beverage $(\mathrm{FB})$, occupation $(\mathrm{O})$, and humiliating condition $(\mathrm{HC})$ [12]. From the 70 respondents who were asked to answer the 28 questions of 11 kinds of the taboo on DCT, it is found that they are 783 data of euphemism. From the analysis, it is identified that the adolescents use euphemism when they are communicating with adults though the taboo words and expressions are provided in the DCT. The obtained euphemism data were, then, analyzed again based on euphemism construction, namely word-formation device, phonemic modification, loan word, and semantic innovation [9]. It is aimed at identifying the WSL usage as a euphemism. The result of the analysis shows that it is the phonemic replacement (425 data) which has the highest construction of euphemism usage. In the phonemic modification, it includes WSL, phonemic replacement, and abbreviation, and most of euphemism in phonemic modification construction is WSL. The following table shows the euphemism construction and the frequency of WSL Usage.

Table. 1. Euphemism Construction, Frequency of WSL Usage

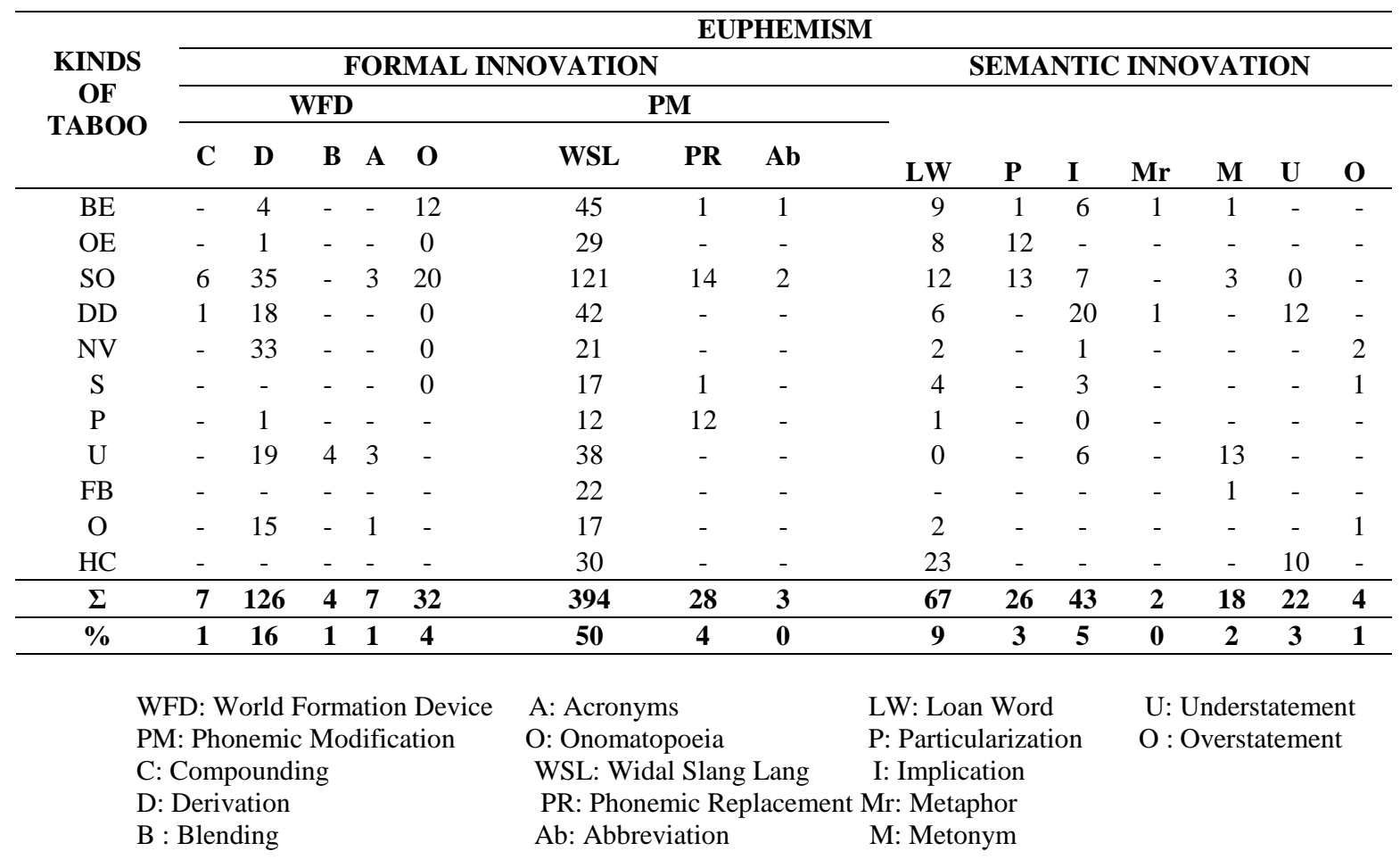

\subsection{WSL usage for Euphemism}

The table shows that there are 394 (50\%) data of WSL usage. The reason why they use the WSL euphemism because they do not know the words or expressions which should be used when they are communicating with adults since Sundanese language has a speech level which is called undak usuk basa as politeness and addressee to whom we talk to [13]. They are afraid of uttering the wrong words/ expression because when they do so, it is impolite and will have a social impact punishment. Therefore, they use the WSL as a 
euphemism to mitigate taboo. The highest usage of WSL shows that it has a contribution to euphemism. Most of the contribution is in the form of words.

Some parts of the bodies and their effluvia are considered to be taboo, and so are the conditions related to the part of bodies, for example, the condition of a woman having menstruation. It is uncomfortable to utter the situation of having menstruation. That is why, women try to hide their condition and find the other expression denoting menstruation, such as kareseban (a soft term for menstruation), nuju aya pamengan (having a hindrance), nији ауа tати (having a visitor) or nuju beureum (in a red condition). However, not all Sundanese speakers in Sukabumi society know such expressions, therefore they use WSL as an alternative of avoiding taboo, it is yeks which is derived from the word "mens" (menstruation). Another part of bodily effluvia is faeces. There are some ways how to replace caduk and tai (faeces) with euphemism, such as using its natural colour si koneng (the yellow), however the respondent use wanyi as a WSL from tai. The word wanyi is usually used when people see or smell faeces either human faeces or animal. Snot is also part of the body included in this category. To avoid the taboo words, it is usually used the phrase of angka sabelas (number eleven), yet the respondents use WSL of rébo. The WSL usage of wanyi and rébo are intended to hide the disgusting object. Of 394 data of WSL usage as euphemism, there are $45(11 \%)$ data of WSL usage for this kind of taboo.

All the body organs producing the bad smell and their activities are categorized as taboo, such as the smell expelled from the mouth or from a hollow part of the body (farting). In addition to the activity, the utterance of the word is also taboo. The words ngabekok and medus (farting) have a smoother word as bobos, but the respondents use WSL of biwuw when they are communicating with adult to hide embarrassment. Telling person about his mouth odour is also taboo. They usually use euphemism "bau baham" (smell of mouth). It turns out that most of the respondents use the WSL of "hanyu" to respect the one whose mouth has a bad smell. Therefore, the WSL usage for organs and their effluvia, as well as their activities, is amounted to $29(7 \%)$ data.

All the human's sexual organs are taboo [14] even when uttering them. The breast which is one of the female genitals has a smooth term to utter for the comfort of communication. It is pinareup (something in front). Sometimes, it is used the euphemism of gunung (mountain), or applying direction word ituna and taeunna (that one), susu, and nénén (breast). However, not all respondents use those euphemisms. Some of them use WSL as an alternative to change taboo. The WSL of susu is gugu. The following is the example how the WSL of gugu is used.

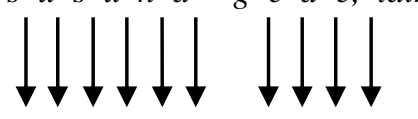

WSL : Oh, awewe nug и g и $k$ a s e p é, lain?

English : Oh, the girl with the big breast, right?

In the phrase guguka sepé, the change occurs from "s" to "g", "n" to "k", "g" to "s", and "d" to "p". The vowel does not change because it is put in the middle of each word. The sentence "Oh, awewe nu guguka sepé, lain?" is usually expressed while casting a glance at the object (woman's breast) but certainly, without the woman's knowledge. Another female genital is a vagina. The smoothest word to utter the word is "gagaduhan" (belonging), "palawangan" (door), or using euphemism of direction words "ituna" and "taeunna" but the respondents are more familiar with the word yéyén, a WSL. A male genital "kanjut" (penis) is usually replaced by "manuk" (bird) or "cau" (banana), or using child language like "titit" or "mamas". For this part of body, respondents use WSL of nakcuw to replace taboo. All WSL usages of human's sexual organ is used when they are talking about it secretly because it is considered to be a discomfort topic in conversation. Meanwhile, the activities done by the body organs are also taboo to utter. "Modol" 
(defecating) and "kiih" (urinating) could be replaced by the phrase of "ka jamban" (going to toilet), "ka pengker" (going to the back), "ka cai" (to the water), or using child language of "Ee" and "pipis" yet the respondents also use yopor of WSL for defecating and choose ninyig WSL for urinating to hide disgusting activity. Sexuality and insults belong to taboo [15], even the sexual intercourse in the most significant taboo [16] and so are its activity and utterance. There are many ways to express sexual intercourse in Sundanese, such as "moék" (staying in the darkness), "nyakeudeung" (short time), "kukudaan" (riding horse), instead of the taboo "ngewe" and "ngentot" (making love). Most of the respondents neither use the taboo expressions, they use other euphemism. It is nyété, a WSL which are used by the respondents to hide discomfort topic of conversation. Thus the respondents who use WSL for the taboo of sexual organs and their activities are 121 (31\%).

The diseases which are considered to be taboo are the embarrassing ones, like mental diseases (insane) and the diseases which are considered to be countrified (deaf). The reference toward disease appears in the utterance of WSL as euphemism. It is the word sero, which means crazy/insane. However, the WSL is used to prevent anger. It is hurt to say "gelo" to a person who is insane, particularly to his/her family. Such a word is usually hidden with the smoother phrases like "kirang sehat" (less healthy), "teu damang emutan" (memory sickness), or with the euphemism of "kirang saalit" (little less). Séro, a WSL is mostly used by the respondents.

Telling torék (deaf) is also hurt for the one who has the disease. To replace the word, the phrase of "kirang ngadangu" (less hearing) is usually used. However, the respondents use a WSL (wolén) to replace the word torék. The words séro and torék are used to respect both the person who has the disease and their family. There are some ways to say someone's death for the politeness, like "ngantunkeun" (leaving), "tilar dunya" (leaving the word), "almarhum" (the late), "jenat" and "pupus" (pass away). It is surprising that most of the respondents still use WSL euphemism for expressing someone's death. The respondents prefer using yanyow (die), a WSL to avoid taboo of death. The number of using WSL for disease and death is $42(11 \%)$ data.

Descriminating with colour of skin is an act of racism [17], therefore it is taboo to utter it especially when uttered with the purpose of insulting [18]. He calls it as racist language because in his opinion the word black in English refers to a black person that is associated to weakness and evil, such as "blackguard" and "blacklist". Meanwhile, the word "white" refers to sincerity, purity, cleanliness, as well as sanctity. Though when one mentions the colour of skin is just for joking, it is taboo to say. The following is a sentence in WSL referring to the mention of skin colour in Sundanese:

Sundanese $\quad$ :tuh si $h$ i deung, datang,

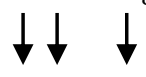

WSL : tuh si $b$ i peung datang,

English : See, the black one is coming.

The word hideung is substituted with bipeung by changing the consonants " $\mathrm{h}$ " into "b" and "d" into "p", while the vowel "i" does not change at all. The other letters that do not undergo any changes are "e", " $u$ ", " $n$ ", and "g" since the letters are in one unit of syllable which are put in the end of the word. Bipeung is a WSL for black. The sentence of "tuh si bipeung datang." is a euphemism which is expressed in the purpose of not making the hearer feels hurt toward the naming referring to the dark skin colour. Therefore, it will avoid enmity caused by the expression though the expression is actually an insulting one. Naming a person with human character both physically and mentally is taboo in Sukabumi society. The naming of black skin colour is mostly used by the Sundanese speakers in Sukabumi society though the colour is not really black, it's brown. A person will be offended when getting a naming of "si hideung" (the black one). Hence, to disguise the phrase it should be used the phrases "si keling" and "si keteng" (the other words for black colour). They tend to be more comfortable to use a WSL of bipeung instead of saying 
black skin.

Viewing a person is taboo to do, particularly to the unknown person. Hence, a person will be offended when he/she is being viewed. Therefore, she/he will ask a question with a harsh question and rough tone naon manéh neuleu? (why do you stare at me?, or kunaon manéh neléh wae (why do you keep staring at me). Moreover, when the viewing is cynical, it brings to a quarrel and even fights. When a person is in that situation (being stared), then usually she/he will mumble by changing the word neuleu with keureu, a WSL which is used as an alternative for taboo though the number is only 7 data. Such a word is used when she/ he convinces that the person does not know WSL so that it could avoid dispute. The number of data for naming and viewing persons that use WSL is 21 (5\%) data.

Swearing refers to a certain linguistic behaviour using taboo [19] because one of the functions of taboo is for expressing hatred [20]. There are many classification of swearing; genital term,excretory term, animal term, anatomical term, imbecilic term, and general term [21]. However, there is human bad nature swearing found in Sukabumi, and most of swearings used in Sukabumi are human bad nature and animal name. One of the human bad natures is "pibanguseun" (saying bad thing caused by other's bad attitude) and "pikasebeleun" (sucking) or pikareseupeun peureup (delight my fist). The three words are inappropriate to utter though we are in an irritated condition. Alternatively, the utterances are always used in the first and second syllable only; "piba" and "pika". Hence, to avoid dispute, 6 respondents use pikareseupeun peureup which is changed into WSL (pikareuseupeun deuleud). Meanwhile, there is also some animal name usage in swearing, and most of the animal name used for swearing is a dog. In Sukabumi society, swearing which uses the word "anjing" ( $\operatorname{dog})$ is replaced by changing the second syllable of "ing" into "jir", "jrit", and "nying", thus the words are "anjir", "anjrit", or "anying". The WSL of anjing is nyakcing. The word is used to as a mumble to avoid dispute. The number of WSL usage to replace swearing taboo is 17 (4\%) data.

Asking for one's privacy is something hurt, such as asking for marital status, especially regarding on the one who does not have a spouse. Therefore, a question of "Ari ibu randa?" (Are you a widow?) should be avoided. Nevertheless, some respondents still ask about the status by replacing the word randa with lakpa, a WSL for comfort. Another privacy which is taboo to say is the possession of money. A person will hide the situation of not having money. It is because of embarrassment. An expert of Sundanese language in Sukabumi, Rayudin, says that "It is forbidden to say it for it is feared to be considered a prayer and then it becomes a reality. Therefore, to hide the situation it could be replaced by other word refers to "duit" (money) like "cincai" (Chinese), and "nuju teu aya" (it is not available) but most of them use a WSL putiw to reduce shame. Therefore there are 12 (3\%) of respondents who use WSL for privacy taboo as a euphemism.

Talking about underwear is taboo, particularly the woman's underwear. To hide it, it is used the reference of an object too, namely kaca soca (spectacles) for a bra, but most of the respondents use the taboo words of kutang and beha, but nuwang a WSL for bra is mostly used by the respondents. Meanwhile, to hide panties, it can be used the loan word from the Indonesian language which is then shortened, such as "CD" (celana dalam). However, the respondents chose more WSL word, jangjuw instead of the mentioned euphemism. Besides, a sanitary napkin which is usually used by a woman when having her period is also taboo to utter. To replace it, the brand of the sanitary (softex) is used. Sometimes it is referred to a certain food followed by the name of a country producing the sanitary napkin, such as "roti Jepang" (Japanese bread). In fact, some of the respondents use godwen as a WSL to replace sanitary napkin. Thus there are $38(10 \%)$ of the respondents who use WSL to hide underwear utterance. All the WSL usage for this kind of taboo is referred for comfort.

In some part of the world pork is common to consume. However, in Sukabumi pork or "daging babi" is considered taboo to consume since it relates to the Islamic religious rule that is mostly embraced by the society. Therefore, to utter the animal is also taboo. To avoid it, the proscribed word is sometimes replaced by teu halal (not kosher), or by 
pronouncing the first syllable of the word, $b a$ from $b a b i$ (pig) but most of the respondents do not use the replacements. 11 respondents use hahi, a WSL, for euphemism to be more comfortable. In addition, there is also a beverage which is prohibited to consume. It is the intoxicating drinks, like liquor, and telling someone who is consuming the beverage is avoided, moreover when he/she starts to get drunk. To hide it, the télér (over-exhausted) is used. Among the 70 respondents, they still use the avoided words of nginum (drink) and mabok (drunk) though some respondents use a WSL of nyikuy for the one who is drinking liquor which is referred for comfort. The total number of WSL usage for food and beverage taboo is $22(5 \%)$.

An occupation which is taboo to utter is the despicable one; an occupation that anyone can do without any intellectual abilities with low income, such as babu or bujang (servant). The word rencang (friend) is usually used for replacing the two words. However, there is no respondent who uses the word. Most of them (17 respondents) prefer using a WSL of $h a h u$ for a euphemism to respect the one with the occupation.

Poverty and pregnancy before married are two conditions which are considered to be embarrassing. Poverty is an economic inability condition shown by inability of basic needs in food, clothing and shelter [22]. Therefore, some expressions are used to get rid of shame, such as jalmi teu gaduh (a not having person) for poverty and kacilakaan (got an accident) for pregnancy before marriage. In fact, the two terms are not used by the respondents. Most of them use WSL. They are yignik for poverty leukeub for pregnancy before marriage. The number of WSL usage as a euphemism for a humiliating condition is $30(8 \%)$ respondents.

\subsection{Contribution of WSL to Euphemism}

From the analysis it is found that WSL gives some contributions to Euphemism, namely to hide embarrassment, to hide disgusting objects and activity, to conceal discomfort topic of conversation, to show politeness, to comfort, to respect others, and to avoid dispute. The following data shows the contribution of WSL to euphemism. The data are categorized from the WSL usage as a euphemism:

Table.2 Contribution of WSL to Euphemism

\begin{tabular}{|c|c|c|c|c|c|c|c|c|}
\hline \multirow{3}{*}{$\begin{array}{c}\text { Kinds } \\
\text { of } \\
\text { Taboo }\end{array}$} & \multirow{3}{*}{ Parts of Taboo } & & \multicolumn{6}{|c|}{ WSL Contribution to Euphemism } \\
\hline & & & $\mathbf{H}$ & HD & $\mathbf{C}$ & $\mathbf{S}$ & $\mathbf{R}$ & $\mathbf{A}$ \\
\hline & & Euphemism & $\mathbf{E}$ & $\mathbf{O A}$ & & $\mathbf{P}$ & $\mathbf{O}$ & D \\
\hline \multirow[t]{5}{*}{$\mathrm{BE}$} & Menstruation & Yeks & $\sqrt{ }$ & - & - & - & - & - \\
\hline & Faeces & Wanyi & - & $\sqrt{ }$ & - & - & - & - \\
\hline & Snot & Rébo & - & $\sqrt{ }$ & - & - & - & - \\
\hline & Farting & Biwuw & $\sqrt{ }$ & - & - & - & - & - \\
\hline & Mouth Odour & Hanyu & - & - & - & - & $\sqrt{ }$ & - \\
\hline \multirow[t]{6}{*}{$\mathrm{SO}$} & Breast & Gugu & - & - & $\sqrt{ }$ & - & - & - \\
\hline & Vagina & Yéyén & - & - & $\sqrt{ }$ & - & - & - \\
\hline & Penis & Nakcuw & - & - & $\sqrt{ }$ & - & - & - \\
\hline & Defecating & Yopor & - & $\sqrt{ }$ & - & - & - & - \\
\hline & Urinating & Ninyib & - & $\sqrt{ }$ & - & - & - & - \\
\hline & Sexual Intercourse & Nyété & - & - & $\sqrt{ }$ & - & - & - \\
\hline \multirow[t]{3}{*}{ DD } & Mental Disease & Séro & - & - & - & - & $\sqrt{ }$ & - \\
\hline & Countrified Disease & Wolén & - & - & - & - & $\sqrt{ }$ & - \\
\hline & Death & Yanyow & - & - & - & $\sqrt{ }$ & - & - \\
\hline \multirow[t]{2}{*}{ NV } & Human Naming & Bipeung & - & - & $\sqrt{ }$ & - & - & - \\
\hline & Viewing Person & Keureu & - & - & - & - & - & $\sqrt{ }$ \\
\hline \multirow[t]{2}{*}{ S } & Human Bad Nature & Deuleud & - & - & - & - & - & $\sqrt{ }$ \\
\hline & Animal Name & Nyakcing & - & - & - & - & - & $\sqrt{ }$ \\
\hline \multirow[t]{2}{*}{$\mathrm{P}$} & Marital Status & Lakpa & - & - & $\sqrt{ }$ & - & - & - \\
\hline & Possession of Money & Putiw & $\sqrt{ }$ & - & - & - & - & - \\
\hline $\mathrm{U}$ & Bra & Nuwang & - & - & $\sqrt{ }$ & - & - & - \\
\hline
\end{tabular}




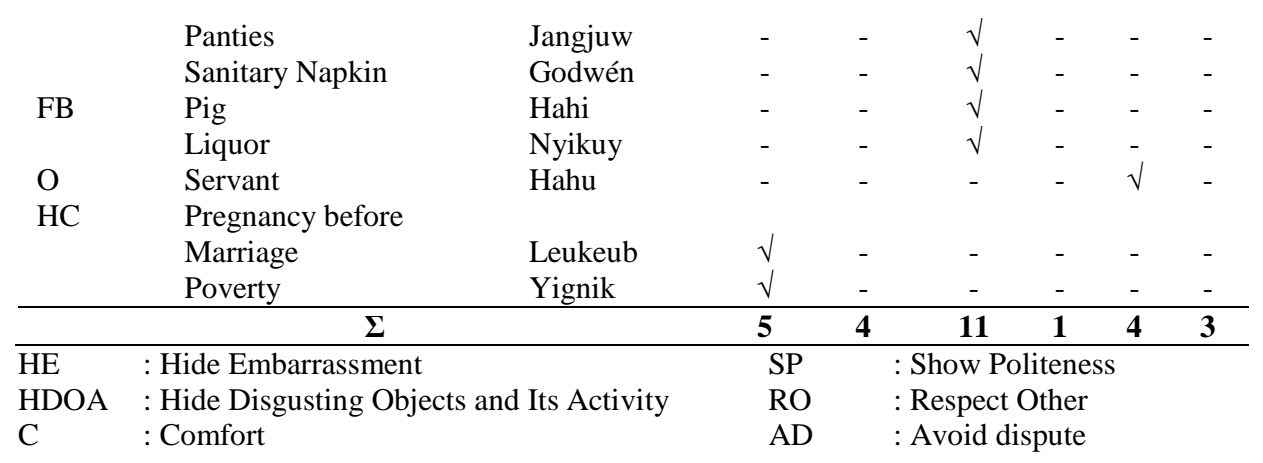

The first contribution of WSL usage to euphemism is to hide embarrassment. Embarrassment also occurs because of wrongdoing which will have a negative effect on the wrongdoer. Therefore, people will prevent doing shameful things or make others embarrass in various ways, one of which is by using euphemism utterance. WSL euphemism is the example of preventing embarrassment from the conditions of 1) having menstruation; particularly for those who have just got their period for the first time, 2) farting in the public place 3) having no money; Euphemism of WSL that refers to the valuable objects like putiw is expressed to hide embarrassment since the condition of having no money is an embarrassing one, 4) being pregnant before marriage, 5) and being poor.

The next WSL contribution to euphemism is to hide disgusting objects and its activity. There are some disgusting objects in our body, such as faeces and snot. Such disgusting objects are considered taboo to utter. It is not only the disgusting objects that are taboo to utter but also the activity related to the objects. To hide such taboo, the people in Sukabumi society make use the WSL.

Sometimes we get involved in a conversation discussing a discomfort topic. To reach a communicative concord, the right utterance should be used. Therefore, some discomfort topics of conversation such as organs of body which are taboo to utter should be changed. The WSL is used in this situation, and this is the most contribution to euphemism that there are 11 parts of taboo using WSL for comfort.

Different societies will use different strategies of politeness for mitigation [23], and so with the societies in Sukabumi city who use of WSL for a euphemism as a strategy of politeness. People will use the right words for politeness, particularly for someone's death. The choice of words to denote someone's death is needed to respect both the family and the dead object [24]. Some WSL which are used as euphemism have the benefit as politeness. When speakers communicate using an inappropriate choice of words, then the communication will not be well established.

The fifth contribution of WSL usage to euphemism is to respect others. In communication, speakers and hearers should respect and appreciate each other.Uttering someone having bad smell of his/her mouth, talking about someone's mental disease and countrified disease are always avoided because they will be offended. Alternatively, the use of WSL for resfect.

To avoid a dispute is the last contribution of WSL usage to euphemism. People use taboo because of some reasons, one of which is to express emotion [25] causing a dispute. A Dispute could occur when we utter unpleasant words that may make the hearers feel hurt. Therefore he/she will reply it with the painful words too which eventually causes dispute. Thus the dispute could be avoided by means of expressing good utterance, and the people in Sukabumi prefer using WSL as a euphemism to avoid dispute.

\section{Conclusion}

WSL as a slang language found in Sukabumi city gives a new nuance to a diversity of 
language since it could contribute to the use of language particularly in communication. WSL is an alternative way used by adolescent when communicating with an adult to express euphemism as a word refinement of avoiding taboo utterance. There are 6 contributions of WSL usage for euphemism, namely to hide embarrassment, disgusting objects and activities, for comfort, to show politeness, to respect others and to avoid dispute. From the findings, it is expected that the contribution of WSL euphemism could add more vocabulary of local language which should be well preserved in order that it will not easily eroded by the rapid development of information and communication media.

\section{References}

[1] Pertala EC, Susilawati L. Widal Slang Language at Tipar Disctrict, Sukabumi City West Java Province, Indonesia. Int J Lang Learn Appl Linguist World. 2016;11(2):86-96.

[2] Kulkarni V, Wang WY. Simple Models for Word Formation in Slang. In: NAACL-HLT. Lousiana: Association for Computational Linguistics; 2018. p. 1424-34.

[3] Amir K, Azisah S. Gender Analysis on Slang Language in Students Daily Conversation. English, Teaching, Learn Res J. 2017;3(2):229-43.

[4] Wu L, Morstatter F, Liu H. SlangSD: Building, Expanding and Using a Sentiment Dictionary of Slang Words for Short-Text Sentiment Classification. Lang Resour Eval. 2018;52(3):839-52.

[5] Yoga Darma Putra IM, Alit Ida Setianingsih NK, Sena Darmasetiyawan IM. Types of Slang Words in the Movie Script of Sausage Party. Humanis. 2018;22(3):796803.

[6] Liyanage I, Walker T, Bartlett B, Guo X. Accommodating Taboo Language in English Language Teaching: Issues of Appropriacy and Authenticity. Lang Cult Curric. 2015;28(2):113-25.

[7] Khoshsaligheh M, Ameri S, Mehdizadkhani M. A Socio-Cultural Study of Taboo Rendition in Persian Fansubbing: an Issue of Resistance. Lang Intercult Commun. 2017;18(6):663-80.

[8] Baltzer-Jaray K. Euphemism. In: Robert, Arp. Stephen, Barbone. Michael B, editor. Bad Arguments. 1st ed. Chichester, UK: John Wiley \& Sons, Ltd; 2019. p. $270-2$.

[9] Warren BC. What Euphemisms Tell Us about the Interpretation of Words. Stud Linguist. 1992;46(2):128-72.

[10] Weaver-Hightower MB. How to Write Qualitative Research. 1st ed. How to Write Qualitative Research. New York: Out of House Publishing; 2019. 15 p.

[11] Sweeney E, Hua Z. Discourse Completion Tasks. In: Hua Z, editor. Research Methods in Intercultural Communication: A Practical Guide. 1st ed. New Jersey: John Wiley \& Sons, Inc; 2016. p. 212-22.

[12] Susilawati L, Gunardi G, Indira D, Citraresmana E. The Usage of Taboo in Sukabumi Society. In: Pourya Asl, Moussa ; Rajandran, Kumaran; Azam Y, editor. International Conference on Linguistics, Literature and Culture. Penang: School of Humanities; 2019. p. 42-5.

[13] Citraresmana E, Wahya W, Djajasudarma F. Sundanese Language Performance of the Elementary School Teacher. In: International Conference on Language Literature, Culture and Education. Bandung: Atlantis Press; 2018. p. 105-11.

[14] Allan K, Burridge K. Forbidden words: Taboo and the censoring of language. 1st ed. New York: Cambridge University Press; 2006. 12 p.

[15] Sulpizio S, Toti M, Del Maschio N, Costa A, Fedeli D, Job R, et al. Are You Really Cursing? Neural Processing of Taboo Words in Native and Foreign Language. Brain Lang. 2019;194(1):84-92.

[16] Agbemenu K, Hannan M, Kitutu J, Terry MA, Doswell W. "Sex Will Make Your Fingers Grow Thin and Then You Die": The Interplay of Culture, Myths, and 
Taboos on African Immigrant Mothers' Perceptions of Reproductive Health Education with Their Daughters Aged 10-14 Years. J Immigr Minor Heal. 2018;20(3):697-704.

[17] Dias DS, Welikala MD, Dias NGJ. Identifying Racist Social Media Comments in Sinhala Language Using Text Analytics Models with Machine Learning. In: International Conference on Advances in ICT for Emerging Regions (ICTer). Colombo: IEEE; 2018. p. 363-8.

[18] Gao C. A Sociolinguistic Study of English Taboo Language. Theory Pract Lang Stud. 2013;3(12):2310-4.

[19] Bednarek M. 'Don't Say Crap. Don't Use Swear Words.' - Negotiating the Use of Swear/Taboo Words in the Narrative Mass Media. Discourse, Context Media. 2019;29(1):1-14.

[20] Primasari D, Alek A, Hidayat D, Hadiyansyah D. Uncovering the Function of Taboo Words Used in "Not Another Teen Movie." In: International Conference on Education in Muslim Society. Jakarta: EAI; 2019. p. 39.

[21] Mahadiputra IGN, Sutjiati Beratha NL, Netra IM. The Form and Use of Swearing Words in the Movie the Wolf of the Wall Street. Humanis. 2018;22(2):416-24.

[22] Khairunnisa D, Noer K. Strategy for Empowering Poor Families through an Integrated Program to Increase the Role of Women towards Prosperous Healthy Families in Depok, West Java. In: International Conference on Social Sciences. Jakarta: EAI; 2019. p. 20.

[23] Ardi H, Nababan MR, Djatmika, Santosa R. Characters' Politeness Strategies in Giving Command: Should Translators Keep Them? Southeast Asian J English Lang Stud. 2018;24(2):181-93.

[24] Sulistyono Y. Struktur dan Fungsi Eufemisme dalam Rubrik Obituari Harian Kompas. LEKSEMA J Bhs dan Sastra. 2016;1(2):73.

[25] Rosenberg P, Sikström S, Garcia D. The A(ffective) B(ehavioral) C(ognitive) of Taboo Words in Natural Language: The Relationship Between Taboo Words' Intensity and Frequency. J Lang Soc Psychol. 2017;36(3):306-20. 